DOI: $10.17805 /$ zpu.2016.4.18

\title{
Основные направления домашнего обучения за рубежом: генезис и типология
}

\author{
И. В. КОЩИЕНКО, Л. И. ПОКРОВСКАЯ \\ (МОСКОВСКИЙ ГУМАНИТАРНЫЙ УНИВЕРСИТЕТ)
}

В статье анализируется смысл понятия «домашнее обучение» («хоумскулинг»), которое часто используется российскими авторами в публикациях, посвященных «семейному образованию». Это одна из вариативных форм обучения ребенка, основанная на желании родителей (законных представителей) дать своему ребенку образование в семье.

Авторы раскрывают генезис идей домашнего обучения и типологию домашнего обучения за рубежом. Среди педагогических направлений выделяются наиболее распространенные: классическое образование (classical education); освобождение от школ (deschooling society); радикальный анскулинг (unschooling). Анализ трансформации указанных направлений охватывает период от 1920-х годов до наших дней. При этом анализируются труды известных зарубежных специалистов в исследуемой области. Подробно изложена позиция философов, педагогов, практиков, изучавших проблему домашнего обучения за рубежом. Среди них: идеи И. Иллича, Дж. Холт, Р. Мур, Д. Мур, Д. Сайерс. Общим для них является убеждение в том, что каждая семья, желающая самостоятельно дать своим детям образование, не уступающее качеством школьному, вполне может с этой задачей справиться. В этой связи использование возможностей семейного образования представляется весьма актуальным и в системе отечественного образования.

Ключевые слова: хоумскулинг; семейное образование; домашнее обучение; история педагогики; история западной педагогики; И. Иллич; Дж. Холт; Р. Мур; Д. Сайерс

\section{ВВЕАЕНИЕ}

$\mathrm{B}$ современном мире предъявляются высокие требования к педагогической науке и практике. Справедливо отмечаются существенные лакуны на различных направлениях педагогики сегодняшнего дня. Практика реализации права родителей на обучение своих детей в различных формах сложна и противоречива.

На наш взгляд, убеждения части современных родителей как в России, так и за рубежом в том, что школа (в силу разных причин) не нацелена на бережное отношение к личности ребенка, вызывает у них желание дать детям образование вне школьных стен (Кощиенко, Покровская, 2015). 
Целью статьи является выделение специфических характеристик, присущих термину «хоумскулинг» («домашнее обучение»), используемому в отечественных публикациях, посвященных семейному образованию.

\section{ГЕНЕЗИС ПОНЯТИЯ «ХОУМСКУАИНГ»}

В России довольно часто употребляется термин «хоумскулинг» (от англ. homeschooling - домашнее обучение), которое по своему значению не соответствует тому же термину, используемому в западных странах. В отечественной педагогической системе то содержание, которое вложено в данное понятие, отражается в термине «семейное образование», утвержденном законодательством Российской Федерации (Федеральный закон ..., 2014: 41).

В зарубежных странах термин «домашнее обучение» имеет весьма широкое значение, включая в себя несколько направлений педагогики. Среди этих направлений можно выделить наиболее распространенные:

- классическое образование;

- освобождение от школ - дескулизация (см.: Аескулизация, 2011: Электронный pecypc);

- свободное обучение - радикальный анскулинг (Анскулинг, 2011: Электронный ресурс).

Суть вышеназванных терминов раскрывается благодаря пониманию генезиса их возникновения.

Еще столетие назад образование во многих странах было практически домашним: общественных учебных заведений было очень мало, и обучение в них было довольно дорогим (равно как и обучение дома при помощи наемных педагогов). Именно по этим причинам обучение детей вынуждены были брать на себя родители, что делало педагогическую составляющую неотделимой от прочих родительских обязанностей. Соответственно, решение о том, чему именно учить ребенка (насколько обширные и насколько глубокие давать знания) и каким образом его учить, - принимали именно родители.

В 20-х годах прошлого века во многих странах произошли изменения, которые затронули и образовательную сферу: теперь граждане большинства стран могли получить бесплатное государственное образование. Результатом введения обязательного государственного образования стал мощный рывок вперед к масштабной индустриальной революции. Однако созданная система государственного обязательного образования повлияла (хоть и не напрямую) и на возникновение проблем: рост подростковой наркомании и преступности, падение академической успеваемости, семейный кризис и т. п. К концу 60-х годов XX столетия вышеназванные проблемы стали настолько актуальными, что привели к появлению первых оппозиционеров общеобразовательной системы.

В 1970 г. австрийским философом и социальным критиком, преподавателем Пенсильванского и Бременского университетов И. Илличем была написана и издана книга «Deschooling society» («Освобождение от школ») (Иллич, 2006: 160). В этой книге автор сделал глубокий анализ негативного влияния обязательной общеобразовательной системы на общество, которое, по его мнению, заключалось в формировании человека, удобного государству - не умеющего мыслить самостоятельно, не умеющего жить вне указанных государством рамок, не имеющего ни воли, ни собственных желаний, стремящегося лишь к потреблению. Исследователь показал, как из активного, 
любознательного, талантливого ребенка общеобразовательная система делает безвольный и посредственный во всех отношениях «винтик» системы. Изменить сложившуюся ситуацию критик предлагал путем отмены обязательного государственного образования. При этом денежные средства, предназначенные госбюджетом на нужды образования, И. Иллич предлагал выплатить родителям, чтобы те смогли потратить их по своему усмотрению.

Хотя критика философа была довольно радикальной, в его книге можно найти и позитивную программу. В частности, автор предлагал создать социальные сети по обмену навыками, чтобы все желающие, посредством контакта с различными специалистами, могли приобрести те или иные навыки или умения. Причем специалисты не должны были быть лицензированными. Аицензированные специалисты, по мнению И. Иллича, как раз являются обслуживающим персоналом государственной системы и творцами этой системы, а следовательно - заинтересованы в понижении общего культурного уровня населения страны. Согласно мнению критика, специалистом может быть любой человек, владеющий каким-либо умением или навыком (вне зависимости от его образования, пола, возраста и т. д.). Кроме этого, реформатор предлагал предоставить детям доступ в различные физические и химические лаборатории, обсерватории, музеи, библиотеки, на функционирующие заводы и фабрики, поскольку только таким образом можно получить полноценное образование.

Вопреки надеждам автора американское правительство не отреагировало на его критику, и никакие изменения в государственную систему образования внесены не были. Однако благодаря труду автора многие родители стали задумываться о домашнем образовании, при котором можно было бы осуществить те идеи, которые изложил философ в своей книге.

Так в Америке и других странах зародилось домашнее обучение.

Американский педагог, разработчик альтернативных методик обучения, защитник прав детей Аж. Холт выпускал периодический информационный бюллетень «Растущий без обучения» (издание о хоумскулинге, анскулинге и внешкольном образовании). Педагог выступал против школьной оценочной системы и тестирования как метода проверки знаний. Школу автор издания называл тем местом, где убивают детское любопытство и интерес. Основными причинами неуспеваемости школьников он считал страх (Коротков, 2001: Электронный ресурс), скуку, разрозненность и бессмысленность учебного материала (Холт, 1996).

Таким образом, независимо от взглядов И. Иллича, зародилось движение Аж. Холта, называемое «радикальный анскулинг» и имеющее свою педагогическую философию - иную, нежели у автора книги «Освобождение от школ» (Коротков, 2001: Электронный ресурс). Отличие состояло в том, что автор бюллетеня «Растущий без обучения» и его единомышленники выступали не только против обязательности общего образования, но и против систематического обучения как такового. Основанием для их убеждений послужил ряд социологических и психологических исследований, которые показали, что обязательное обучение в школе по строгой программе наносит непоправимый вред здоровью и психике детей.

В основу подхода Аж. Холта легла концепция естественного воспитания мыслителя эпохи Просвещения Жан-Жака Руссо (Руссо, 1981). Как и французский философ, А. Холт придерживался мнения, что человек не нуждается в специально организованной познавательной деятельности, наоборот - нужно как можно меньше вмешиваться в естественный ход событий, не мешая ему развиваться самостоятельно. Соответ- 
ственно, следование каким-либо обязательным программам обучения не является ни важным, ни нужным. По мнению американского педагога, не нужны ни системы поощрений и наказаний (и вообще какие-либо педагогические воздействия), ни дисциплина, ни субординация (Холт, 1996). Ребенок растет в семье, развиваясь в своем темпе, следуя своим познавательным интересам, сам выбирая для себя предмет познавательной активности в тот или иной момент времени: «Только сам ребенок может знать, какая именно толика знаний нужна ему в каждый конкретный момент больше всего, подходит к его модели реальности лучше всего... Все, что мы можем, - это оказать ему посильную помощь, поделившись своими знаниями и подсказав, где можно найти более исчерпывающие и подробные сведения. Выбор должен сделать он сам» (там же: 442).

Точки зрения И. Иллича и Аж. Холта были довольно привлекательны для родителей того времени своим либерализмом. Согласно данным концепциям, образование являлось частным делом каждой семьи, а целью образования служило овладение ребенком необходимыми для жизни чисто практическими навыками. Обе системы не рассматривали образование в разрезе воспроизводства культуры, что, возможно, было следствием господствовавшей в те годы культуры хиппи, $\Lambda$ СА и свободной любви.

Переломным моментом в развитии системы взглядов на домашнее образование можно считать инициированное в 1969 г. специалистом Аепартамента образования США Р. Муром движения за легализацию домашнего обучения. Вместе со своей супругой, учителем младших классов Аороти, Р. Мур провел исследование в Медицинской школе Университета штата Колорадо, а также изучил материалы более 8000 различных исследований о раннем обучении и развитии детей. Более всего исследователя интересовали проблемы: правильно ли заключать маленьких детей в рамки формального образования, и в каком возрасте детям лучше всего начинать обучение в школе. Изучая эти вопросы, супруги Мур столкнулись с фактом, что более ста специалистов в области домашнего образования настаивали на том, что нужно быть крайне осторожными, подвергая неокрепшую нервную систему и психику ребенка воздействию формальной системы образования. В результате многолетних исследований в области формального образования и социальной адаптации Р. и А. Мур пришли к выводу, что детей следует как можно дольше оберегать от принудительного школьного образования и по возможности отсрочить поступление в школу до 8-10, а то и 12 лет (Moore R., Moore D., 1986). Аанные исследований были опубликованы в 1972 г. в журнале «Харпер», после чего статья была перепечатана в «Ридерс Аайджест». В 1975 г. вышла первая книга исследователей - « Аучше позже, чем раньше» (Better Late Than Early), затем - «Школа подождет» (School Can Wait). Были также опубликованы книги «Аети, выросшие дома» («Нome grown kids») и «Аоморощенные школы» («Home-spun-schools»), являвшиеся, по сути, практическими руководствами для родителей по семейному обучению. Книги состояли из советов, как самим стать учителями для своих детей и преуспеть в обучении детей в домашних условиях.

В 80-е годы ХХ столетия, вместе с изменением экономической ситуации, для которой был характерен спад производства, изменились и взгляды общества на существующую ситуацию, в том числе в сфере образования. От либеральных взглядов общество отказалось в пользу более консервативных, более трезвых, основанных на традиционных ценностях. В этот период на Западе вспомнили о концепции клас- 
сического образования, сложившейся еще в Средние века (и функционировавшей в те времена в системе традиционной школы). Эта система классического образования стала очень популярной вновь благодаря опубликованному в США эссе А. Сайерс «The Lost Tools of Learning» («Утерянные инструменты обучения»), написанному автором в 1947 г.

А. Сайерс - английская писательница, филолог, драматург, много писавшая также на темы образования и придерживавшаяся мнения, что именно образование является краеугольным камнем критического отношения к действительности. В своем эссе писательница раскритиковала существующую в Великобритании образовательную систему и предложила вернуться к средневековой системе классического образования. По мнению автора, эффективность средневековой системы образования была обусловлена разделением всего курса наук на две части: «тривиум» и «квадриум». И если, изучая «квадриум», студент осваивал набор учебных предметов, то «тривиум» «... на самом деле был призван привить ученику правильное применение инструментов учебы, прежде чем начнется применение их к “предметам”» (там же). То есть чрезвычайно важно научить ребенка учиться, прежде чем учить его конкретным предметам и дисциплинам. Речь идет о тренировке памяти, умения логически мыслить, аргументировать свою позицию, умения четко и лаконично выражать свои мысли (как в письменной, так и в устной форме). К сожалению, современные ученики не вполне владеют этими навыками, хотя общеобразовательная система и декларирует их освоение в школе. Но поскольку развитие вышеперечисленных навыков в общеобразовательной школе не является первостепенным, а лишь идет на фоне изучения предметов, 一 то и результат такого развития стремится к нулю.

Автор адаптировала для нашего времени средневековую систему обучения, включив в нее следующие этапы:

- грамматический (овладение базовыми учебными инструментами: чтением, письмом, запоминанием и воспроизведением информации);

- диалектический (тренировка умения выстраивать логические связи между полученными из различных предметных областей знаниями; основным учебным инструментом на данном этапе становится умение четко и ясно доносить свои мысди до аудитории, участвуя в дискуссиях);

- риторический (развитие навыков красноречия путем написания сочинений по различным предметам и защиты написанных работ перед различными комиссиями).

Эссе «Утраченные инструменты обучения» способствовало возникновению нового направления в образовании - неоклассического подхода. После выхода эссе Ауглас Уилсон (пастор Общины Евангельского Братства в г. Москоу, штат Айдахо, США, и редактор журнала Credenda/Agenda) опубликовал в 1991 г. статью «Восстановление утраченных инструментов обучения», что послужило толчком к открытию в США ряда школ, основанных на образовательном подходе, предложенном Аороти Сайерс. Этот подход заинтересовал и американских хоумскулеров, что сделало домашнее обучение интересным не только для семей с весьма либеральными взглядами, но и для более широкой аудитории, заинтересованной дать своим детям качественное образование.

Окончательно привлекательным для хоумскулеров классическое образование стало после выхода в 1999 г. книги «Хорошо тренированный ум: Справочник по Классическому Образованию дома». Авторам удалось ответить на множество вопросов в области классического образования. С того момента и до сих пор книги этих авторов 
являются настольными методическими пособиями для родителей обучающих детей дома. В настоящий момент, по данным статистики, приведенным Национальным центром статистики образования (National Center for Education Statistics), по системе homeschooling в США обучается около полутора миллионов детей.

\section{ЗАКАЮЧЕНИЕ}

Резюмируя вышеизложенное, хотелось бы подчеркнуть, что выбор методической и учебной литературы, служащей цели дать качественное классическое образование детям, обучающимся в семье, в настоящее время довольно обширен. Благодаря этому каждая семья, желающая самостоятельно дать своим детям образование, не уступающее качеством школьному, вполне может с этой задачей справиться, о чем свидетельствуют многочисленные исследования.

Кроме того, семейное образование становится все более популярным как за рубежом, так и в России. Аети-хоумскулеры продолжают обучение в высших учебных заведениях (Гарвард, Стэнфорд, Принстон, Аартмутский колледж и др.), при этом часто показывают хорошие результаты при поступлении в вузы, благодаря чему отношение к хоумскулингу в мире меняется в лучшую сторону.

\section{СПИСОК АИТЕРАТУРЫ}

Федеральный закон «Об образовании в Российской Федерации» : по сост. на 2014 год: с коммент. юристов (2014). М. : Эксмо. 800 с.

Анскулинг (2011) [Электронный ресурс] // Альтернативная педагогика. 25 мая. URL: http://alternativepedagogy.wordpress.com/2011/05/25/unschooling/ (дата обращения: 06.11.2014).

Аескулизация (2011) [Электронный ресурс] // Альтернативная педагогика. 24 мая. URL: http://alternativepedagogy.wordpress.com/2011/05/24/deschooling/ (дата обращения: 02.11.2014).

Иллич, И. (2006) Освобождение от школ. Пропорциональность и современный мир : пер. с нем. и англ. М. : Просвещение. 149 с.

Коротков, А. (2001) Кто стряхнет со школы паутину страха? Заметки о педагогических воззрениях Ажона Холта [Электронный ресурс] // Первое сентября. № 69. URL: http://ps.1september.ru/article.php?ID=200106906 (дата обращения: 01.11.2015).

Кощиенко, И. В., Покровская, $\Lambda$. И. (2015) Семейное образование как вариантивная форма обучения // Знание. Понимание. Умение. № 4. С. 187-193. DOI: 10.17805/zpu.2015.4.17

Руссо, Ж.-Ж. (1981) Эмиль, или О воспитании // Руссо, Ж.-Ж. Педагогические сочинения : в 2 т. М. : Педагогика. Т.1. 665 с. С. $25-244$.

Холт, Аж. (1996) Причины детских неудач : пер. с англ. СПб. : Кристалл ; Аельта. 442 с.

Moore, R. S., Moore, D. (1986) When Education Becomes Abuse: A Different Look at the Mental Health of Children // Journal of School Health February. Vol. 56, №2. P. 73-75. DOI: 10.1111/j.1746-1561.1986.tb01178.x

Аата поступления: 12.10 .2016 г.

HOMESCHOOLING OUTSIDE RUSSIA: GENESIS AND TYPOLOGY

I. V. KOSHCHIENKo, L. I. POKROVSKaIA

(MOSCOW UNIVERSITY FOR THE HUMANITIES)

The article examines the idea of homeschooling - a notion often appealed to by Russian authors in their works on "family education". Homeschooling is an alternative form of education based on parents' (or legal guardians') desire to provide the child with education in the family. 
In the article, we outline the genesis of homeschooling ideas, as well as the typology of homeschooling abroad, with a special focus on the most popular pedagogical theories, such as classical education, deschooling society and unschooling. The article covers the transformations these theories have undergone since the 1920s. We analyze the works of most prominent Western specialists in this field - philosophers, educators, practitioners who have written on the issue of homeschooling, such as I. Illich, J. Holt, R. Moore, D. Moore and D. Sayers. A common point for all of them is their conviction that every family wishing to provide their children with school-class education can achieve this goal. This makes using homeschooling techniques and achievements relevant for the Russian educational system as well.

Keywords: homeschooling; family education; home tuition; history of pedagogy; history of pedagogy in the West; I. Illich; J. Holt; R. Moore; D. Sayers

\section{REFERENCES}

Federal' nyi zakon "Ob obrazovanii v Rossiiskoi Federatsii» : po sost. na 2014 god: s komment. iuristov (2014). Moscow, Eksmo. 800 p. (In Russ.)

Anskuling (2011). Al'ternativnaia pedagogika, 25 May [online] Available at: http://alternativepedagogy.wordpress.com/2011/05/25/unschooling/ (access date: 06.11.2014). (In Russ.)

Deskulizatsiia (2011) Al'ternativnaia pedagogika, 24 May [online] Available at: http://alternativepedagogy.wordpress.com/2011/05/24/deschooling/ (access date: 02.11.2014). (In Russ.)

Illich, I. (2006) Osvobozbdenie ot shkol. Proportsional'nost' $i$ sovremennyi mir. Moscow, Prosveshchenie. 149 p. (In Russ.)

Korotkov, A. (2001) Kto striakhnet so shkoly pautinu strakha? Zametki o pedagogicheskikh vozzreniiakh Dzhona Kholta. Pervoe sentiabria, no. 69 [online] Available at: http://ps.1september.ru/article.php?ID=200106906 (access date: 01.11.2015). (In Russ.)

Koshchienko, I. V. and Pokrovskaia, L. I. (2015) Semeinoe obrazovanie kak variantivnaia forma obucheniia. Znanie. Ponimanie. Umenie, no. 4, pp. 187-193. DOI: 10.17805/zpu.2015.4.17 (In Russ.)

Rousseau, J.-J. (1981) Emil', ili O vospitanii. In: Rousseau, J.-J. Pedagogicheskie sochineniia : in 2 vols. Moscow, Pedagogika. Vol. 1. 665 p. Pp. 25-244. (In Russ.)

Holt, J. (1996) Prichiny detskikb neudach. St. Petersburg, Kristall, Del'ta. 442 p. (In Russ.)

Moore, R. S. and Moore, D. (1986) When Education Becomes Abuse: A Different Look at the Mental Health of Children. Journal of School Health February, vol. 56, no. 2, pp. 73-75. DOI: 10.1111/j.1746-1561.1986.tb01178.x

Submission date: 12.10 .2016$.

Кощиенко Ирина Васильевна - кандидат педагогических наук, доцент кафедры педагогики и психологии высшей школы Московского гуманитарного университета. Адрес: 111395, Россия, г. Москва, ул. Юности, д. 5. Тел.: +7 (499) 374-70-53. Эл. адрес: ds2723@mail.ru

Покровская Аариса Игоревна - бакалавр кафедры педагогики и психологии высшей школы Московского гуманитарного университета. Адрес: 111395, Россия, г. Москва, ул. Юности, А. 5. Тел.: +7 (499) 374-56-11. Эл. адрес: larapokrovckaya@gmail.com. Научный руководитель канд. пед. наук И. В. Кощиенко.

Koshchienko Irina Vasilievna, Candidate of Pedagogy, Associate Professor, Department of pedagogy and psychology of higher school, Moscow University for the Humanities. Postal address: 5 Yunosti St., 111395 Moscow, Russian Federation. Tel.: +7 (499) 683-59-30.E-mail: ds2723@mail.ru

Pokrovskaia Larisa Igorevna, Bachelor student, Department of pedagogy and psychology of higher school, Moscow University for the Humanities. Postal address: 5 Yunosti St., 111395 Moscow, Russian Federation. Tel.: +7 (499) 374-56-11. E-mail: larapokrovckaya@gmail.com. Research advisor: Candidate of Pedagogy, Associate Professor I. V. Koshchienko. 